\title{
Antidiuretic Hormone Measurement
}

National Cancer Institute

\section{Source}

National Cancer Institute. Antidiuretic Hormone Measurement. NCI Thesaurus. Code C74847.

The determination of the amount of antidiuretic hormone present in a sample. 